\title{
Energia e desenvolvimento sustentável no Brasil em comparação internacional
}

Giorgio Romano Schutte

Universidade Federal do $A B C$ (UFABC)

Este artigo pretende abordar as potencialidades do Brasil no esforço global rumo a uma economia de baixo carbono utilizando dados comparativos internacionais. Nesse campo, o País passou por uma trajetória muito diferenciada que o colocou, aparentemente, em grande vantagem em relação aos demais. Além de possuir uma matriz comparativamente mais limpa, demonstrou capacidade de provocar uma redução expressiva das emissões de gases de efeito estufa (GEE). Por outro lado, essas conquistas podem desestimular ulteriores avanços necessários. Como país em desenvolvimento, o Brasil tem um duplo desafio: criar as condições para um desejado aumento do padrão de vida para sua população, o que exige disponibilidade de recursos energéticos, e, ao mesmo tempo, procurar uma eficiência energética, aumentando o rendimento da energia disponível. Um dos grandes gargalos e desafios é o setor de transportes, em particular transporte rodoviário.

Palavras-chave: desenvolvimento sustentável, energia renovável, conservação da energia, eficiência energética, política energética, transporte

\section{Energía y desarrollo sostenible en Brasil en comparación internacional}

Este artículo pretende abordar los potenciales de Brasil en el esfuerzo global rumbo a una economía de bajo carbono utilizando datos comparativos internacionales. En este campo, el país hizo una trayectoria peculiar que lo puso en una situación de aparente ventaja en comparación con los demás. Además de poseer una matriz comparativamente más limpia, demostró capacidad para reducir las emisiones de gas de efecto invernadero (GEI) de forma significativa. Por otra parte, tales conquistas pueden desestimular ulteriores

[Artigo submetido em maio de 2014. Versão final em fevereiro de 2015.] 
avances necesarios. Como país en desarrollo, Brasil se enfrenta un doble desafío: crear las condiciones para el ansiado aumento del nivel de vida de su población, que exige de la disponibilidad de recursos energéticos, y, a la vez, buscar mayor eficiencia energética, aumentando el rendimiento de la energía disponible. Uno de los grandes "cuellos de botella" y desafíos es el sector de transportes, en particular el transporte automotor.

Palabras clave: desarrollo sostenible, energía renovable, conservación de la energia, eficiencia energética, política energética, transporte

\section{Energy and sustainable development in Brazil: an international comparison}

This article focuses on Brazil's potential in the global effort towards a low-carbon economy, highlighting the interfaces with energy policies. Brazil's reality will be compared with international data. Brazil followed a very different track which has put the country in an advantage. Besides having a comparatively clean matrix, it has shown the capacity to advance a significant reduction in Greenhouse Gas (GHG) emissions. Being a developing country, Brazil has a double challenge: create conditions to increase the standards of living of its population, which means to assure energy security and, at the same time, invest in efficiency, making the best use of available energy. On the other hand, these gains might reduce the pressure for further advances. One of the big challenges is for sure the transport sector, in particular road transport.

Keywords: sustainable development, renewable energy, energy conservation, energy efficiency, energy policy, transportation 


\section{Introdução}

No século 21, a discussão em torno da mudança climática alterou o olhar sobre a política energética no âmbito global. O ponto de partida é que a emissão de gases de efeito estufa (GEE), em particular dióxido de carbono, metano e óxido nitroso, provoca aquecimento global, com consequências para a instabilidade climática, provocando um aumento estatístico dos desastres naturais com grandes impactos, inclusive para a produção alimentar. Neste artigo, pretende-se analisar a especificidade da posição do Brasil nesse debate.

Diante da ausência de reservas de energia fósseis conhecidas e exploráveis e das restrições financeiras externas, o projeto de industrialização no Brasil encontrou caminhos alternativos no desenvolvimento de hidrelétricas e etanol. Os primeiros investimentos na década de 1930 e grandes investimentos na década de 1970 geraram acesso a fontes nacionais, exploradas e produzidas com tecnologia e equipamentos de capacidade endógena. É preciso lembrar que, até a década de 1970, as fontes de energia predominantes no País eram o petróleo ( $80 \%$ importado) e a lenha (IPEA, 2010). Assim, quando o mundo foi confrontado com a relação entre a queima de energia fóssil e a crescente instabilidade climática, o Brasil se encontrava em situação relativamente confortável no que diz respeito à sua matriz energética. A questão da mudança climática provocou a necessidade de buscar alternativas às energias fósseis por outros motivos, além do seu esgotamento.

Como país em desenvolvimento, o Brasil tem um duplo desafio: criar as condições para um desejado aumento no padrão de vida da sua população - o que exige disponibilidade de recursos energéticos - e, ao mesmo tempo, tentar reduzir o crescimento da demanda, sem comprometer o padrão de qualidade de vida, e aumentar a participação de fontes renováveis com domínio tecnológico endógeno.

O 4을 Relatório do Painel Intergovernamental sobre Mudança do Clima (IPCC na sigla inglesa) de 2007 pode ser considerado um ponto de inflexão importante pelo impacto da afirmação de que é muito provável que a ação humana seja a causa do aquecimento global. Considerando que, em nível global, a energia é responsável por cerca de dois terços dos GEE (INTERNATIONAL ENERGy AgENCY, 2013a), as políticas se concentraram, sobretudo, na busca de fontes de energia de baixo carbono e no uso mais eficiente da energia gerada. Sem dúvida, não existe energia limpa, pois, em maior ou menor grau, todas as fontes provocam danos ao meio-ambiente ao longo de seu ciclo de produção. Nesse sentido, a economia mais limpa é aquela em que se consegue economizar. 
Carlos Nobre, Secretário de Políticas e Programas de Pesquisa e Desenvolvimento do Ministério da Ciência e Tecnologia (MCT) e membro do IPCC, afirmou que "o Brasil, antes do 4을 Relatório, tinha uma posição. Após, ele começa a articular outra posição"1.

A responsabilidade pela coordenação das ações no governo migrou da Comissão Interministerial de Mudança Global do Clima, criada em 1999 e vinculada ao MCT, para o Comitê Interministerial sobre Mudança do Clima (CIM), ligado à Casa Civil. Foi o CIM que elaborou, em 2008, o Plano Nacional sobre Mudança do Clima (PNMC), um plano de ação que deveria coordenar não só as ações dos diversos órgãos da esfera federal, mas também articular-se com estados e municípios. No ano seguinte, na $\operatorname{COP}^{2} 15$, em Copenhagen, numa reviravolta da posição brasileira, o governo assumiu compromissos nacionais voluntários com metas de redução das emissões na faixa de 36,1\% a 38,9\% em relação à sua projeção para 2020 (ano base 2005). Chama a atenção que, nessas projeções, a contribuição da energia no total de emissões de GEE iria aumentar de $15 \%$ para $27 \%$, patamar ainda distante dos $65 \%$ da média mundial. Em termos nominais, as emissões ligadas diretamente à produção e ao consumo de energia deverão aumentar de 329 milhões de toneladas de dióxido de carbono $\left(\mathrm{tCO}_{2}\right)$, em 2005, para 868 milhões de $\mathrm{tCO}_{2}$, em 2020.

Os compromissos nacionais voluntários foram incluídos na codificação do Plano Nacional sobre Mudança do Clima (Lei no 12.187, de 29 de dezembro de 2009), regulamentado em 9 de dezembro de 2010 pelo Decreto no 7390 . A lei instalou planos setoriais de mitigação e adaptação à mudança do clima. Em 2011 e 2012, foram elaborados os planos setoriais das áreas de indústria, mineração, transporte/ mobilidade urbana e saúde.

A partir do decreto de 2010, o Plano Decenal de Expansão de Energia $(P D E)^{3}$, elaborado anualmente pela Empresa de Pesquisa Energética (EPE), vinculada ao Ministério de Minas e Energia (MME), passa a ser considerado um dos planos setoriais de mitigação e adaptação às mudanças climáticas.

\footnotetext{
${ }^{1}$ Entrevista no programa Roda Viva, da TV Cultura, 19/08/2013. http://tvcultura.cmais.com.br/rodaviva/ roda-viva-carlos-nobre-19-08-2013-bloco-1

${ }^{2}$ A Conferência das Partes (COP) é o órgão supremo decisório no âmbito da Convenção sobre Diversidade Biológica (CDB), um tratado da Organização das Nações Unidas (ONU) fruto da ECO-92 - a Conferência das Nações Unidas sobre Meio Ambiente e Desenvolvimento (CNUMAD), realizada no Rio de Janeiro em junho de 1992. As quatro primeiras reuniões da COP foram realizadas anualmente. A partir da quinta reunião, a COP passou a se reunir de dois em dois anos. Trata-se de uma reunião de grande porte que conta com a participação de delegações oficiais dos 188 membros da CDB, 187 países e a União Europeia, observadores de países não participantes, representantes dos principais organismos internacionais, organizações acadêmicas, organizações não governamentais, organizações empresariais, lideranças indígenas, imprensa e demais observadores.

${ }^{3} \mathrm{O}$ objetivo do planejamento decenal da expansão do sistema energético nacional consiste em se definir um cenário de referência para implementação de novas instalações na infraestrutura de oferta de energia.
} 
O Art 6으, inciso III, do decreto, estipula que, para alcançar os compromissos nacionais voluntários, é preciso:

expansão da oferta hidroelétrica, da oferta de fontes alternativas renováveis, notadamente centrais eólicas, pequenas centrais hidroelétricas e bioeletricidade, da oferta de biocombustíveis e incremento da eficiência energética (BRASIL, 2010).

Com relação aos biocombustíveis, o decreto estipulou como meta ampliar em $11 \%$ ao ano, nos próximos dez anos, o consumo interno de etanol. No geral, e da mesma forma que acontece nas demais economias, também no Brasil há uma inércia para entrar em uma nova trajetória, não obstante a existência de um marco legal avançado. Importante lembrar que o Brasil é um dos países com maior potencial de energia renovável, somando água, vento, sol, maré, biomassa; mas o seu aproveitamento depende de políticas científico-tecnológicas e priorização política.

Inevitavelmente, surgiram resistências por parte de setores econômicos diretamente envolvidos, diante do risco de perda de competitividade internacional. Investimentos na transição para uma economia de baixo carbono têm o potencial de mitigar os impactos negativos das mudanças climáticas, mas também de economizar custos em médio e longo prazo. O problema é que, em curto prazo, na ausência de obrigação ou coordenação internacional, haverá aumento de custos, diante dos quais a indústria alerta para um conflito com sua competitividade internacional.

Dado o cenário descrito acima, este artigo irá discutir a posição do Brasil nesse debate. $\mathrm{O}$ artigo está dividido em duas partes. Na primeira, é apresentada a matriz energética relativamente mais limpa e o impacto das políticas públicas voltadas para a diminuição do desmatamento, até então a principal fonte de GEE no Brasil. Ainda será apresentada uma comparação do consumo de energia e GEE per capita do Brasil com padrões internacionais. Na segunda parte, será analisado o que é chamado de "nova realidade". Com a queda significativa do desmatamento, a energia, em particular a que é ligada ao transporte, ganha um papel de destaque na análise dos GEE no Brasil. Especialmente a excessiva dependência do transporte de cargas sobre rodas se tornou um dos principais obstáculos para o controle dos GEE.

\section{Matriz energética diferenciada}

Oresultado do esforço para garantir condições de crescimento, sem constrangimentos externos, gerou uma matriz energética bastante diferenciada no Brasil, se comparada internacionalmente. Embora os esforços no campo de etanol e hidrelétrica não tenham sido motivados pelo desejo de gerar uma matriz de baixo carbono, foi esse o resultado. O que parecia uma maldição tornou-se um trunfo: a escassa existência de carvão e a relativa demora na descoberta de petróleo em grandes volumes. 
Tabela 1: Comparação entre a matriz energética no mundo e no Brasil (dados referentes a 2010)

\begin{tabular}{l|c|c}
\hline Energia & Mundo & Brasil \\
\hline Petróleo & $32 \%$ & $37,5 \%$ \\
\hline Carvão & $\mathbf{2 8 \%}$ & $5,3 \%$ \\
\hline Gás natural & $21 \%$ & $10,3 \%$ \\
\hline Nuclear & $\mathbf{6 \%}$ & $\mathbf{1 , 4} \%$ \\
\hline Hidrelétrica & $\mathbf{2 \%}$ & $\mathbf{1 4 , 1} \%$ \\
\hline Derivados de cana & $\mathbf{0 \%}$ & $\mathbf{1 7 , 5 \%}$ \\
\hline Outros & $\mathbf{1 1 \%}$ & $\mathbf{1 3 , 9 \%}$ \\
\hline Total & $100 \%$ & $100 \%$ \\
\hline
\end{tabular}

Fonte: Secretaria de Planejamento e Desenvolvimento Energético do Ministério de Minas e Energia (2014).

A Tabela 1 mostra o peso relativamente alto das fontes renováveis na matriz energética brasileira. Em negrito, as fontes que contribuem com uma matriz de baixo carbono. Em itálico, as fontes consideradas renováveis. Assim, enquanto a matriz energética mundial é composta por $81 \%$ de combustíveis fósseis, esse número é de $53 \%$ no Brasil. Isso devido ao fato de a participação de fontes renováveis chegar a $45 \%$ no Brasil, contra 13\% no mundo. No caso da matriz para energia elétrica, a particularidade da matriz energética brasileira é mais evidente ainda, como mostra a Tabela 2.

Tabela 2: Comparação entre a matriz de energia elétrica no mundo e no Brasil (dados referentes a 2010)

\begin{tabular}{l|c|c}
\hline Energia & Mundo & Brasil \\
\hline Carvão & $41 \%$ & $1,3 \%$ \\
\hline Gás natural & $22 \%$ & 5,7 \\
\hline Hidrelétrica & $16 \%$ & $74,3 \%$ \\
\hline Nuclear & $13 \%$ & $2,7 \%$ \\
\hline Petróleo & $5 \%$ & $2,7 \%$ \\
\hline Derivados de cana & 0 & $5,1 \%$ \\
\hline Outros & $3 \%$ & $8,2 \%$ \\
\hline Total & $100 \%$ & $100 \%$ \\
\hline
\end{tabular}

Fonte: Secretaria de Planejamento e Desenvolvimento Energético do Ministério de Minas e Energia (2014).

Nesse caso, as fontes de origem fóssil representam $68 \%$ mundialmente, contra $10 \%$ no Brasil, devido à utilização de fontes renováveis, que chegam a $86 \%$ no Brasil, contra somente $18 \%$ globalmente.

A Tabela 3 mostra a relativa estabilidade da participação de várias fontes na produção de energia, com ligeira queda da hidráulica e lenha, e pequeno aumento da participação da bioenergia. 
Tabela 3: Evolução percentual da produção de energia no Brasil de 2006 a 2012

\begin{tabular}{|l|r|r|r|r|r|r|r|}
\hline & \multicolumn{1}{|c|}{2006} & \multicolumn{1}{|c|}{2007} & \multicolumn{1}{|c|}{2008} & \multicolumn{1}{|c|}{2009} & \multicolumn{1}{|c|}{2010} & \multicolumn{1}{|c|}{2011} & \multicolumn{1}{|c|}{2012} \\
\hline Petróleo & 42,1 & 40,6 & 39,7 & 42 & 42,1 & 42,5 & 41,6 \\
\hline Gás natural & 8,3 & 8,1 & 9 & 8,7 & 9 & 9,3 & 9,9 \\
\hline Carvão vapor & 1 & 1 & 1,1 & 0,8 & 0,8 & 0,8 & 1 \\
\hline Urânio & 1,1 & 1,6 & 1,7 & 1,7 & 0,7 & 1,6 & 1,5 \\
\hline Hidráulica & 14,2 & 14,4 & 13,4 & 14 & 13,7 & 14,4 & 13,9 \\
\hline Lenha & 13,5 & 12,8 & 12,4 & 10,2 & 10,3 & 10,1 & 10 \\
\hline $\begin{array}{l}\text { Produtos da } \\
\text { cana de açúcar }\end{array}$ & 16,6 & 18,1 & 19 & 18,6 & 19,3 & 16,9 & 17,5 \\
\hline $\begin{array}{l}\text { Outras } \\
\text { renováveis }\end{array}$ & 3,2 & 3,4 & 3,6 & 3,9 & 4,1 & 4,4 & 4,6 \\
\hline Total & $\mathbf{1 0 0 \%}$ & $\mathbf{1 0 0 \%}$ & $\mathbf{1 0 0 \%}$ & $\mathbf{1 0 0 \%}$ & $\mathbf{1 0 0 \%}$ & $\mathbf{1 0 0 \%}$ & $\mathbf{1 0 0 \%}$ \\
\hline
\end{tabular}

Fonte: Empresa de Pesquisa Energética (2013).

O Gráfico 1 mostra a evolução da capacidade de produção do etanol ao longo das últimas décadas, que fez do Brasil, até hoje, o único país onde o etanol (hidratado) é vendido como combustível sem ser misturado com gasolina. Além disso, o etanol (anidro) é misturado à gasolina para baratear o combustível, aumentar sua octanagem e reduzir a emissão de poluentes. O governo brasileiro anunciou, em meados de 2014, a intenção de aumentar a mistura na proporção de $25 \%$ para 27,5\%, valor considerado máximo devido à necessidade de haver alteração no motor para além dessa proporção. Mais de 40 países, como Estados Unidos e China, também utilizam essa mistura, porém, em proporções entre 5\% a 10\%.

\section{Gráfico 1: Evolução da produção de cana-de-açúcar no Brasil}

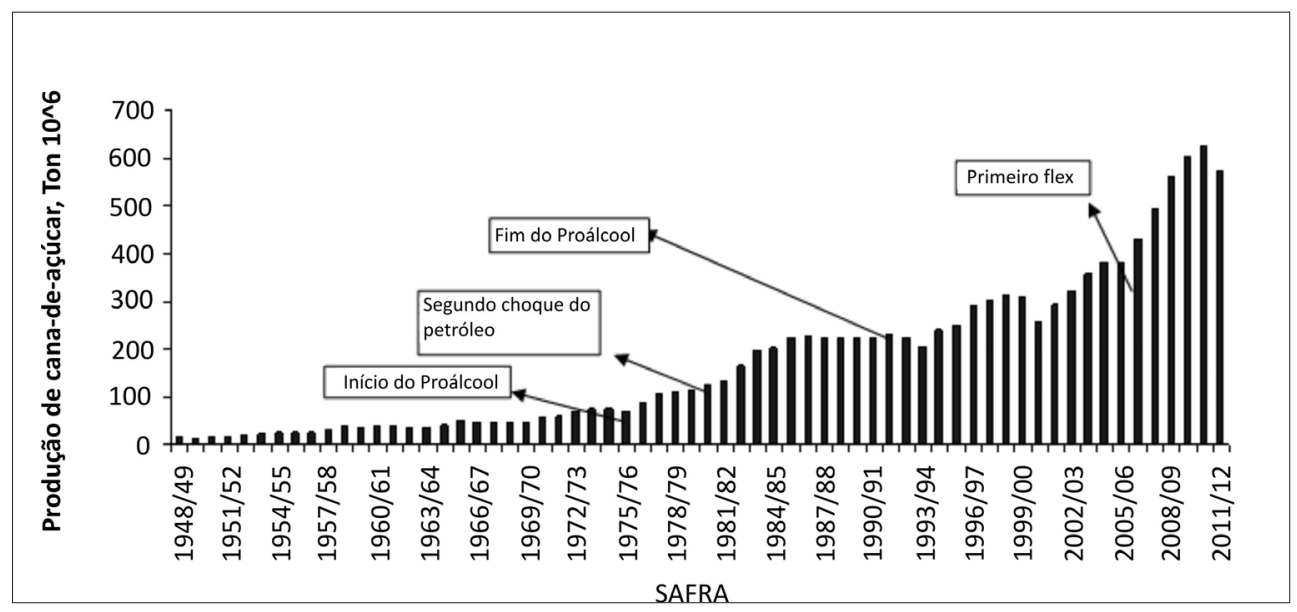

Fonte: Departamento de Ciências Agrárias e Ambientais (DCAA) da Universidade Estadual de Santa Cruz; Secretaria de Produção de Agroenergia (SPAE/Mapa); União da Indústria de Cana-de-Açúcar (Unica) e Ministério da Agricultura, Pecuária e Abastecimento (Mapa); e União dos Produtores de Bioenergia (Udop). Os dados a respeito das safras de 2010/2011 e 2011/2012 (estimativa) são da Companhia Nacional de Abastecimento (Conab). Elaboração própria. 
O Brasil se consolidou como segundo mercado consumidor de biocombustíveis, somente superado pelos EUA, conforme pode ser observado na Tabela 4.

Tabela 4: Consumo de biocombustível (etanol e biodiesel) em TJ

\begin{tabular}{|l|c|c|c}
\hline Países $\backslash$ Ano & 2005 & 2010 & 2012 \\
\hline EUA & 337.941 & 1.012 .973 & 1.070 .660 \\
\hline Brasil & 291.533 & 588.900 & 517.495 \\
\hline Alemanha & 81.259 & 123.947 & 120.873 \\
\hline Mundo & 777.604 & 2.377 .504 & 2.498 .871 \\
\hline
\end{tabular}

Fonte: PBL Netherlands Environmental Assessment Agency/ European Comission (2013). ${ }^{4}$

No caso da hidrelétrica, a primeira usina entrou em operação no final do século 19, e a primeira fase de expansão estava sob controle de empresas originárias dos EUA e do Canadá. Em 1939, registrou-se uma capacidade instalada de energia hidrelétrica de $884 \mathrm{MW}$, que, sob comando estatal, iria se expandir, chegando a $80.600 \mathrm{MW}$ em 2010. Importante nessa trajetória foi a criação da holding estatal Eletrobrasil, em 1962, com suas empresas cobrindo as várias Regiões: a Eletronorte, na Região Norte; Chesf, na Região Nordeste; e Furnas, na Região Sul. Outro ponto marcante foi a entrada em operação, em 1984, da binacional Itaipu, após 10 anos do início da sua construção. Era a maior hidrelétrica do mundo, com capacidade de $14.000 \mathrm{MW}$, fruto da ação estratégica dos Planos Nacionais de Desenvolvimento (PND) I e II.

\section{Matriz de baixo carbono e grande emissor?}

Em tese, essa matriz diferenciada deveria ficar evidente, também, diante da atenção que o mundo começou a dar às emissões de gases de efeito estufa (GEE). Mas, no primeiro momento, isso não ocorreu, devido a outra particularidade da realidade brasileira: as queimadas, principalmente na Floresta Amazônica, de grandes áreas, como parte da lógica selvagem de expansão de terras agrícolas, com destaque para a produção de soja e carnes, além da própria madeira. Elas foram durante muito tempo, de longe, a principal fonte de emissão de GEE no Brasil, registradas como mudanças do uso da terra e florestas, na sigla inglesa LUCF Land Use Change and Forest (ASSUNÇÃO; GANDOUR; ROCHA, 2012). Ou seja, a matriz energética de baixo carbono ficou escondida detrás da fumaça das queimadas. $O$ Primeiro Inventário Brasileiro de Emissões Antrópicas de Gases de Efeito Estufa foi

\footnotetext{
${ }^{4}$ http://edgar.jrc.ec.europa.eu.
} 
publicado em dezembro de 2004 e se referia ao período 1990-19945. O segundo inventário nacional (MINISTÉRIO DA CIÊNCIA E TECNOLOGIA, 2010) referia-se ao período 1990-2005 e identificava uma participação das emissões da energia de 16,48\% no total das emissões de GEE do Brasil. No caso do desmatamento, calculou-se 64,1\%.

E foi justo nesse campo que o Brasil conseguiu avanços significativos, pouco conhecidos pelo público leigo e, sobretudo, pouco valorizados no mundo e até no Brasil. O Gráfico 2 mostra essa trajetória.

Gráfico 2: Trajetória do desmatamento na Amazônia Legal ${ }^{6}$ em 1000 km² 1988 a 2012

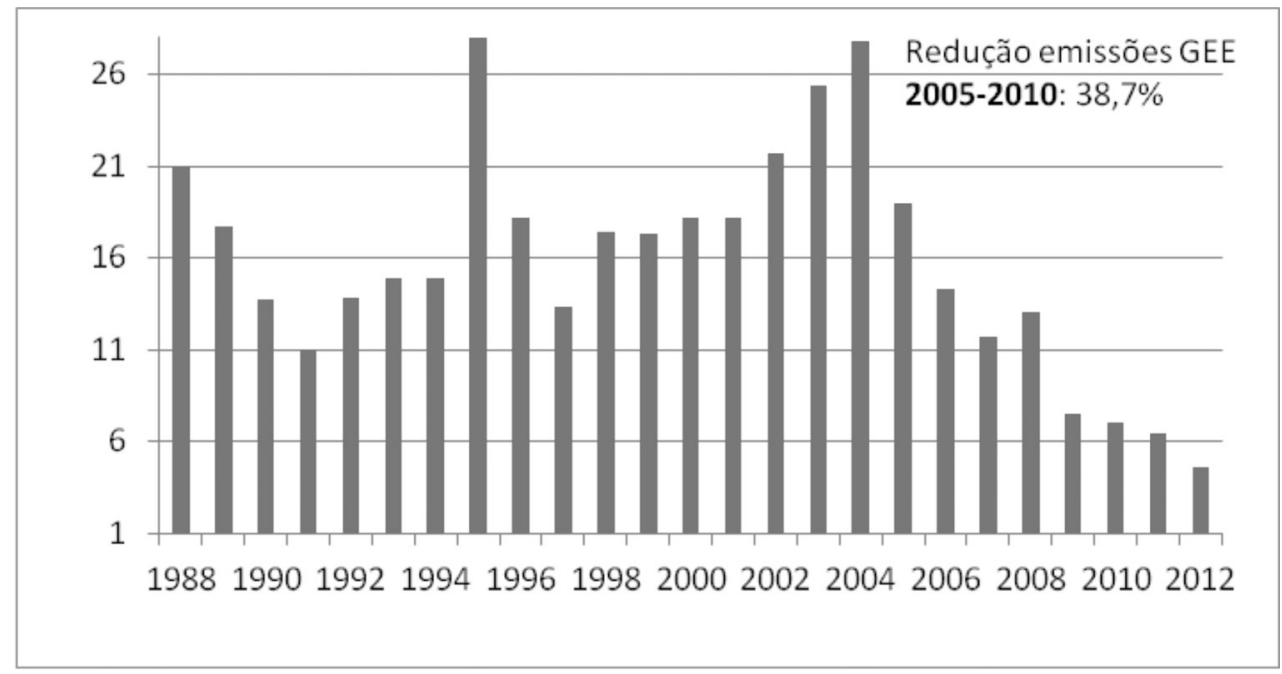

Fonte: Instituto Nacional de Pesquisa Espacial (2014)․

O Brasil conseguiu, a partir de 2004, por meio de uma série de políticas coordenadas e do monitoramento avançado realizado pelo Instituto Nacional de Pesquisa Espacial (INPE), reduzir o desmatamento de uma média de 20.000 km², no período de 2001-2004, para $12.000 \mathrm{~km}^{2}$, no período 2005-2009, e 7200 km²,

\footnotetext{
${ }^{5}$ http://www.mct.gov.br/index.php/content/view/17341.html

${ }^{6}$ O conceito de Amazônia Legal foi instituído em 1953 no âmbito do Plano de Valorização Econômica da Amazônia, e seus limites territoriais decorrem da necessidade de planejar o desenvolvimento econômico da região. Originalmente, a Amazônia Legal englobava a totalidade de oito estados (Acre, Amapá, Amazonas, Mato Grosso, Pará, Rondônia, Roraima e Tocantins) e parte do Estado do Maranhão (a oeste do meridiano de 44W). Os limites da Amazônia Legal foram alterados várias vezes em consequência de mudanças na divisão política do País. O Plano Amazônia Sustentável (PAS), lançado em 2008, considera integralmente o Estado do Maranhão como parte da Amazônia Brasileira.

${ }^{7}$ Disponível em: <http://www.obt.inpe.br/prodes/index.php>. Acessado em: 20 de abril de 2014.
} 
no período 2009-2010 (ASSUNÇÃO; GANDOUR; ROCHA, 2012). Há de se considerar que a queda do desmatamento, verificada em menor escala no início da década de 1990, coincidiu com uma conjuntura de crise econômica interna e depressão dos preços dos produtos de agroexportação envolvidos no desmatamento. Nesse sentido, a forte queda verificada na última década chama ainda mais atenção, pois coincide com uma fase de expansão da economia interna e forte valorização dos preços dos produtos agrícolas nos mercados internacionais, em particular a carne e a soja. Pode-se afirmar, portanto, que não se trata de pontos fora da curva, mas de uma alteração estrutural nas políticas públicas e sua eficácia. Baseado nessa conquista, o Brasil conseguiu se apresentar como campeão de redução de GEE: -38,7\% no período entre 2005 e 2010, fato inédito no mundo. A participação das queimadas no total de emissões brasileiras caiu de 57,5\% em 2005 para 22,4\% em 2010, alterando de forma significativa o padrão de emissões. Em 2012, o Brasil registrou uma emissão de GEE proveniente da queima de energia fóssil nas térmicas superior às emissões causadas pelo desmatamento (ver Tabela 5). Com base nessa conquista, o Fórum de Meio Ambiente do Setor Elétrico (FMASE), por exemplo, defendeu em um positon paper apresentado na véspera do COP 15 em dezembro de 2009:

Entendemos que o Brasil deve ter reconhecido seu esforço para desenvolver uma matriz energética baseada em fontes renováveis, quer seja no que se refere aos biocombustíveis, quer seja na energia elétrica. Ao contrário dos países desenvolvidos, onde, em geral, o setor de energia é o principal responsável pelas emissões de GEE, a matriz energética brasileira é uma das mais limpas no mundo, tendo $47 \%$ de fontes renováveis, sendo que a matriz elétrica contribui grandemente para essa condição com cerca de $89 \%$ de fontes renováveis. O País tem, portanto, um "Crédito Ambiental Histórico", em contraste às "responsabilidades históricas" dos países desenvolvidos relativas às grandes emissões passadas. As negociações devem explorar essas vantagens comparativas do Brasil (FóRUM DE MEIo AMBIENTE do SETOR ELÉTRICO, 2009).

Ao mesmo tempo, os avanços expressivos na redução do desmatamento mudaram a composição das fontes de emissão de GEE no Brasil, como pode ser observado na Tabela 5. Embora as queimadas ainda constituam uma fonte importante de emissões de GEE, surgem como fontes principais de emissões de GEE a agropecuária e a energia. 
Tabela 5: Evolução da emissão de GEE por fonte em $\mathrm{Gg} \mathrm{CO} 2$ equivalente no Brasil

\begin{tabular}{l|c|c|c|c|}
\hline & $\mathbf{1 9 9 0}$ & $\mathbf{2 0 0 0}$ & \multicolumn{1}{c|}{$\mathbf{2 0 0 5}$} & \multicolumn{1}{|c|}{$\mathbf{2 0 1 0}$} \\
\hline $\begin{array}{l}\text { Energia } \\
\text { (incluindo } \\
\text { transportes) }\end{array}$ & 191.543 & 301.096 & 328.808 & 399.302 \\
\hline $\begin{array}{l}\text { Processos } \\
\text { industriais } \\
\text { (excluindo } \\
\text { o uso de } \\
\text { energia) }\end{array}$ & 52.536 & 71.673 & 77.943 & 82.048 \\
\hline Agropecuária & 303.776 & 347.878 & 415.713 & 437.226 \\
\hline Florestas & 815.965 & 1.324 .371 & 1.167 .917 & 279.163 \\
\hline Resíduos & 28.939 & 38.550 & 41.880 & 48.737 \\
\hline Total & 1.392 .756 & 2.083 .570 & 2.032 .260 & 1.246 .477 \\
\hline
\end{tabular}

Fonte: Ministério da Ciência, Tecnologia e Inovação (2013).

Obs. Os dados referentes a 1990, 2000 e 2005 constam também no banco de dados da UNFCC, embora com números ligeiramente diferentes. Disponível em: <http://unfccc.int/di/DetailedByParty/ Event.do?event=go>

De acordo com o World Resource Institute (WRI, 2010), em nível mundial, a energia (incluindo transportes) é responsável por 64,4\% dos GEE, sendo esse valor $77,9 \%$ na União Europeia e 87,1\% nos EUA ${ }^{8}$. A Tabela 6 mostra a evolução da energia no total de emissões de GEE no Brasil

Tabela 6: Evolução da participação de energia no total de GEE no Brasil

\begin{tabular}{|c|c|c|c|}
\hline $\mathbf{1 9 9 0}$ & $\mathbf{2 0 0 0}$ & $\mathbf{2 0 0 5}$ & $\mathbf{2 0 1 0}$ \\
\hline $13,7 \%$ & $14,5 \%$ & $16 \%$ & $32 \%$ \\
\hline
\end{tabular}

Fonte: Ministério da Ciência, Tecnologia e Inovação.

\section{Relativo baixo consumo per capita}

Outra característica da realidade brasileira que deve ser levada em consideração em análises sobre o presente e, sobretudo, projeções e cenários futuros, é o relativo baixo consumo de energia per capita.

\footnotetext{
8 De acordo com a classificação do IPCC, as demais fontes de GEE são: processos industriais (não considerando uso de energia); uso de solventes e outros produtos; agropecuária; mudanças do uso da terra e florestas; e tratamento de resíduos.
} 
Gráfico 3: Consumo de energia per capita em kg óleo equivalente - 2011



Fonte: Banco Mundial (2014) ${ }^{9}$

As Tabelas 7, 8 e 9 colocam a realidade do consumo de energia per capita no Brasil em comparação com a realidade em outros países.

Tabela 7: Comparação do consumo de energia no Brasil com seleção de países desenvolvidos - em kg óleo equivalente per capita

\begin{tabular}{c|c|c|c|c|c}
\hline País & $\mathbf{1 9 8 0}$ & $\mathbf{1 9 9 0}$ & $\mathbf{2 0 0 0}$ & $\mathbf{2 0 0 8}$ & $\mathbf{2 0 1 1}$ \\
\hline EUA & $\mathbf{7 9 4 2}$ & 7672 & 8057 & 7488 & 7032 \\
\hline Austrália & 4737 & 5053 & 5645 & 5766 & 5501 \\
\hline $\begin{array}{c}\text { Países } \\
\text { Baixos }\end{array}$ & 4549 & 4393 & 4598 & 4837 & 4638 \\
\hline Alemanha & 4562 & 4421 & 4094 & 4075 & 3822 \\
\hline Japão & 2950 & 3556 & 4091 & 3879 & 3610 \\
\hline Itália & 2318 & 2584 & 3012 & 2942 & 2664 \\
\hline Brasil & 935 & 937 & 1074 & 1296 & 1371 \\
\hline
\end{tabular}

Fonte: Banco Mundial (2014).

\footnotetext{
${ }_{9}^{9}$ Disponível em <http://data.worldbank.org/indicator/EG.USE.PCAP.KG.OE>. Acessado em 21/04/2014.
} 
Tabela 8: Comparação do consumo de energia no Brasil com alguns países latinoamericanos - em kg óleo equivalente per capita

\begin{tabular}{c|c|c|c|c|c}
\hline País & $\mathbf{1 9 8 0}$ & $\mathbf{1 9 9 0}$ & $\mathbf{2 0 0 0}$ & $\mathbf{2 0 0 8}$ & $\mathbf{2 0 1 1}$ \\
\hline Venezuela & 2347 & $\mathbf{2 2 0 6}$ & 2312 & 2475 & 2380 \\
\hline Argentina & 1487 & 1412 & 1652 & 1961 & 1967 \\
\hline Chile & 847 & 1060 & 1629 & 1801 & 1940 \\
\hline México & 1352 & 1423 & 1400 & 1582 & 1588 \\
\hline Brasil & 935 & 937 & 1074 & 1296 & 1371 \\
\hline Bolívia & 445 & 384 & 440 & 607 & 746 \\
\hline
\end{tabular}

Fonte: Banco Mundial (2014).

Tabela 9: Comparação do Brasil com alguns outros países em desenvolvimento em kg óleo equivalente per capita

\begin{tabular}{c|c|c|c|c|c}
\hline País & $\mathbf{1 9 8 0}$ & $\mathbf{1 9 9 0}$ & $\mathbf{2 0 0 0}$ & $\mathbf{2 0 0 8}$ & $\mathbf{2 0 1 1}$ \\
\hline $\begin{array}{c}\text { Arábia } \\
\text { Saudita }\end{array}$ & 3160 & 3687 & 5030 & 5844 & 6738 \\
\hline $\begin{array}{c}\text { Coreia do } \\
\text { Sul }\end{array}$ & 1081 & 2171 & 4003 & 4636 & 5260 \\
\hline África do Sul & 2371 & 2584 & 2483 & 2961 & 2741 \\
\hline China & 847 & 1060 & 1629 & 1801 & 1940 \\
\hline Turquia & 716 & 977 & 1209 & 1400 & 1539 \\
\hline Brasil & 935 & 937 & 1074 & 1296 & 1371 \\
\hline Índia & 294 & 365 & 439 & 539 & 614 \\
\hline
\end{tabular}

Fonte: Banco Mundial (2014).

Além do relativo baixo consumo do Brasil, não só em comparação com países desenvolvidos e grandes produtores de petróleo, mas também em relação a países no mesmo estágio de desenvolvimento, os dados apresentados mostram algumas tendências. Países frios gastam mais pela necessidade de aquecimento. Países produtores de petróleo tendem a ter um comportamento de uso intensivo, devido ao baixo custo de energia. De resto, as grandes disparidades refletem as diferenças de renda no mundo, mas fica evidente que essa relação não é linear, o que se evidencia, por exemplo, se compararmos o uso de energia nos EUA com o de países europeus como Alemanha e França ou com o Japão. O diferencial se explica, somente em parte, pela maior renda per capita.

A matriz mais limpa do Brasil se expressa também na comparação internacional das emissões de $\mathrm{CO}_{2}$, conforme pode ser observado na Tabela 10 . 
Tabela 10: Emissões CO2: trajetória per capita e números totais para 2012

\begin{tabular}{c|c|c|c|c|c}
\hline & $\begin{array}{c}\text { Emissões } \\
\text { totais em } \\
\text { milhões de } \\
\text { toneladas } \\
\mathbf{2 0 1 2}\end{array}$ & $\begin{array}{c}\text { Emissões } \\
\text { per } \\
\text { capita em } \\
\text { toneladas } \\
\mathbf{1 9 9 0}\end{array}$ & $\begin{array}{c}\text { Emissões } \\
\text { per } \\
\text { capita } \text { em } \\
\text { toneladas } \\
\mathbf{2 0 0 0}\end{array}$ & $\begin{array}{c}\text { Emissões } \\
\text { per } \\
\text { capita } \text { em } \\
\text { toneladas } \\
\mathbf{2 0 1 0}\end{array}$ & $\begin{array}{c}\text { Emissões } \\
\text { per } \\
\text { capita em } \\
\text { toneladas } \\
\mathbf{2 0 1 2}\end{array}$ \\
\hline EUA & 5.200 & 19,6 & 20,6 & 17,6 & 16,4 \\
\hline $\begin{array}{c}\text { Coreia do } \\
\text { Sul }\end{array}$ & 640 & 5,9 & 9,8 & 12,2 & 13 \\
\hline Alemanha & 810 & 12,7 & 10,4 & 9,9 & 9,7 \\
\hline $\begin{array}{c}\text { União } \\
\text { Europeia }\end{array}$ & 3.700 & 9,1 & 8,4 & 7,8 & 7,4 \\
\hline China & 9.900 & 2,1 & 2,8 & 6,4 & 7,1 \\
\hline México & 490 & 3,6 & 3,6 & 3,9 & 4 \\
\hline Brasil & 460 & 1,5 & 2 & 2,2 & 2,3 \\
\hline Índia & 1.970 & 0,8 & 1 & 1,5 & 1,6 \\
\hline
\end{tabular}

Fonte: PBL Netherlands Environmental Assessment Agency/ European Comission (2013).

Embora haja inegável potencial para aumentar a eficiência energética, é necessário reconhecer o estágio de desenvolvimento do País, que aponta para uma elasticidade da demanda por energia com relação ao crescimento do PIB superior a 1, como pode ser observado na Tabela 11.

Tabela 11: Relação da variação do PIB real e do consumo de energia elétrica no Brasil

\begin{tabular}{c|c|c}
\hline Ano & PIB & $\begin{array}{c}\text { Consumo } \\
\text { energia elétrica }\end{array}$ \\
\hline 2010 & $7,5 \%$ & $8,2 \%$ \\
\hline 2011 & $2,7 \%$ & $4,2 \%$ \\
\hline 2012 & $1 \%$ & $3,5 \%$ \\
\hline 2013 & $2,3 \%$ & $3,5 \%$ \\
\hline
\end{tabular}

Fonte: Ministério de Minas e Energia/Empresa de Pesquisa Energética (2013).

As conquistas descritas acima (a matriz energética mais limpa, o consumo per capita relativamente baixo e a redução drástica de emissão de GEE) podem desestimular reflexões críticas e desincentivar o aproveitamento de potenciais para ulteriores avanços rumo a uma economia de baixo carbono. Isso ocorre ainda mais em um contexto no qual a questão da segurança energética e restrições externas no campo da energia para o crescimento econômico parecem ter se afastado 
definitivamente, com as recentes descobertas de petróleo nas províncias do présal, cujas reservas são estimadas entre 50 bilhões e 100 bilhões de petróleo e gás.

A Tabela 12 projeta a evolução do uso de energias renováveis entre 2011 e 2035 usando dois cenários: um que se limita a uma estratégia "mais do mesmo", chamado de políticas existentes, e outro que projeta o resultado de implementação de fato das novas estratégias e investimentos já anunciados pelos respectivos governos, chamado novas políticas.

Tabela 12: Uso de energia renovável para atender a demanda primária de energia (2011)

\begin{tabular}{l|c|c|c}
\hline & $\mathbf{2 0 1 1}$ & $\begin{array}{c}\text { Com políticas } \\
\text { existentes: 2035 }\end{array}$ & $\begin{array}{c}\text { Com novas } \\
\text { políticas: 2035 }\end{array}$ \\
\hline EUA & 140 & 282 & 331 \\
\hline União Europeia & 183 & 326 & 362 \\
\hline China & 298 & 445 & 509 \\
\hline Brasil & 116 & 204 & 207 \\
\hline
\end{tabular}

Fonte: International Energy Agency (2013b).

O que chama a atenção é que, no caso do Brasil, praticamente não foram identificados esforços adicionais que se traduzissem em uma diferença entre o resultado de políticas existentes e o da implementação de novas políticas. Em parte, isso pode ser explicado pela situação avançada na qual o Brasil já se encontra, mas, sem dúvida, outro fator é a acomodação que leva à resistência em investir pesado em novos avanços.

Na Tabela 13, observamos uma projeção de queda da participação das fontes renováveis do Brasil de 87,1\% em 2011 para 79,5\% em 2035. Enquanto isso, os demais países devem fazer o caminho inverso, aumentando a participação de renováveis, sem alcançar, porém, os níveis do Brasil. A projeção da queda da participação das fontes renováveis está relacionada diretamente às limitações socioambientais: $60 \%$ do potencial de energia hidráulica no Brasil se encontram na Bacia Amazônica, envolvendo os rios Tocantins, Araguaia, Xingu e Tapajós, com impacto potencial nas reservas florestais, parques nacionais e terras indígenas. Diante dessa realidade, o governo brasileiro trabalha com a impossibilidade de explorar o potencial físico da hidroeletricidade no Brasil (Tolmasquim; Guerreiro; Gorini, 2007). 
Tabela 13: Expansão das fontes renováveis na eletricidade com implementação de novas políticas ${ }^{10}$

\begin{tabular}{l|c|c|c|c}
\hline & 2011 TWh & $2011 \%$ total & 2035 TWh & $2035 \%$ total \\
\hline Brasil & 463 & $87,1 \%$ & 862 & $79,5 \%$ \\
\hline EUA & 544 & $12,6 \%$ & 1211 & $23 \%$ \\
\hline $\begin{array}{l}\text { União } \\
\text { Europeia }\end{array}$ & 696 & $21,4 \%$ & 1580 & $43,8 \%$ \\
\hline China & 814 & $17,1 \%$ & 2804 & $28 \%$ \\
\hline Mundo & 4482 & $20,3 \%$ & 11612 & $31,3 \%$ \\
\hline
\end{tabular}

Fonte: International Energy Agency (2013).

O Brasil não deixou de ser alvo de fortes críticas, sobretudo de movimentos ambientalistas internacionais e nacionais, mas também de setores da academia. Primeiro, durante anos, o alvo foi o desmatamento da Amazônia. Acontece que a queda significativa não encontrou o mesmo reconhecimento. Ao contrário, é comum que se volte a falar da questão quando há um aumento na margem, porque a queda do desmatamento não se dá de forma linear. Segundo, o etanol foi alvo de duras críticas por sua suposta insustentabilidade social (exploração e superexploração da mão de obra), ambiental (provocaria necessariamente desmatamento) e socioeconômica (provocaria um processo de expulsão da produção de alimentos e, por isso, seria responsável pelo aumento dos preços de alimentos básicos da população). Assim, de carro-chefe da contribuição brasileira rumo a uma economia de baixo carbono, o etanol se viu no banco dos réus. Não se analisou a especificidade do etanol brasileiro em comparação com biocombustíveis produzidos em outros ambientes e não se considerou a capacidade da sociedade brasileira de atacar os problemas sociais e ambientais, que, no contexto, não são inerentes à produção do etanol, mas produtos de relações sociais e políticas do setor sucroalcooleiro e, portanto, sujeitos a alteração, inclusive sob a pressão das críticas. E, por último, as próprias hidrelétricas, de símbolos de uma geração de eletricidade de baixo carbono, tornaram-se vilãs de violação dos direitos dos povos indígenas e outras comunidades atingidas pelas barragens.

Muitas das críticas são legítimas e importantes para provocar adequações necessárias, mas, ao não se reconhecer os avanços alcançados pelo Brasil, graças à utilização dessas fontes, para uma estratégia de crescimento com uma matriz de baixo carbono, se bloqueia qualquer diálogo construtivo. Assim, o Brasil se tornou

\footnotetext{
10 O World Energy Outlook (WEO) 2013 da Agência Internacional de Energia calcula a necessidade de investimentos em um valor total de mais de US\$ 6 trilhões para a realização dessa expansão de energia elétrica produzida por fontes renováveis.
} 
um país onde, no mesmo dia, se pode assistir a um encontro de acadêmicos e movimentos sociais que o aponta como exemplo do atraso diante dos desafios da mudança climática e, de outro lado, a um encontro que envolve outros stakeholders, enfatizando sua liderança com a matriz de baixo carbono, se comparado internacionalmente. Tanto o não reconhecimento dos avanços realizados quanto a acomodação diante da comparação internacional dificultam a priorização de ações concretas para que o Brasil possa, de fato, se consolidar e afirmar sua posição de liderança na luta global rumo a uma economia de baixo carbono.

\section{Nova realidade}

Com a queda do desmatamento, houve uma mudança qualitativa, e o desafio agora é outro. A energia, que estava em segundo plano, aparece como a principal área que exige políticas específicas.

No caso da energia, houve um crescimento forte das emissões (Tabela 15), em particular dos transportes (Tabela 16). Isso significa que, nessa nova fase, a prioridade deve ser dada à alteração da matriz de transporte, superando o que hoje se destaca como a singularidade da realidade brasileira: a grande participação do transporte sobre rodas para cargas. Bem como se precisa superar, de outro lado, o atraso em encontrar soluções de transporte público de massa, que não acompanhou a forte expansão da frota automobilística a partir de meados da década de 2000.

Interessante também é observar a distribuição do crescimento do uso de energia elétrica (ver Tabela 14). A queda relativa da demanda por energia elétrica pelo setor industrial, a partir de 2011, reflete os problemas pelos quais a indústria está passando no Brasil, como uma tendência à relativa desindustrialização, com investimentos produtivos baixos. Não foi resultado de esforços em aumentar a eficiência energética. Logo, a aposta em defesa da indústria brasileira deverá - se for exitosa - resultar em um aumento ainda maior da elasticidade renda/consumo de energia. Em 2010, o setor industrial respondeu por 39,6\% do total de consumo de energia no Brasil, caindo, em 2012, para 35,1\% e, em 2013, para 33,9\% (EMPRESA DE Pesquisa EnergéticA, 2014).

Tabela 14: Crescimento anual do uso de energia elétrica por setor no Brasil

\begin{tabular}{c|c|c|c|c}
\hline & Residencial & Comercial & Industrial & Total \\
\hline 2010 & $6,4 \%$ & $6,0 \%$ & $10,9 \%$ & $8,2 \%$ \\
\hline 2011 & 4,4 & 6,2 & 2,3 & 4,2 \\
\hline 2012 & 5,1 & 7,8 & $-0,1$ & 3,5 \\
\hline 2013 & 6,1 & 5,7 & 0,6 & 3,5 \\
\hline
\end{tabular}

Fonte: Ministério de Minas e Energia/Empresa de Pesquisa Energética (2013). 
O Gráfico 4 apresenta a participação no consumo de energia dos diversos setores em 2012.

\section{Gráfico 4: Percentual de consumo de energia por setor (2012)}

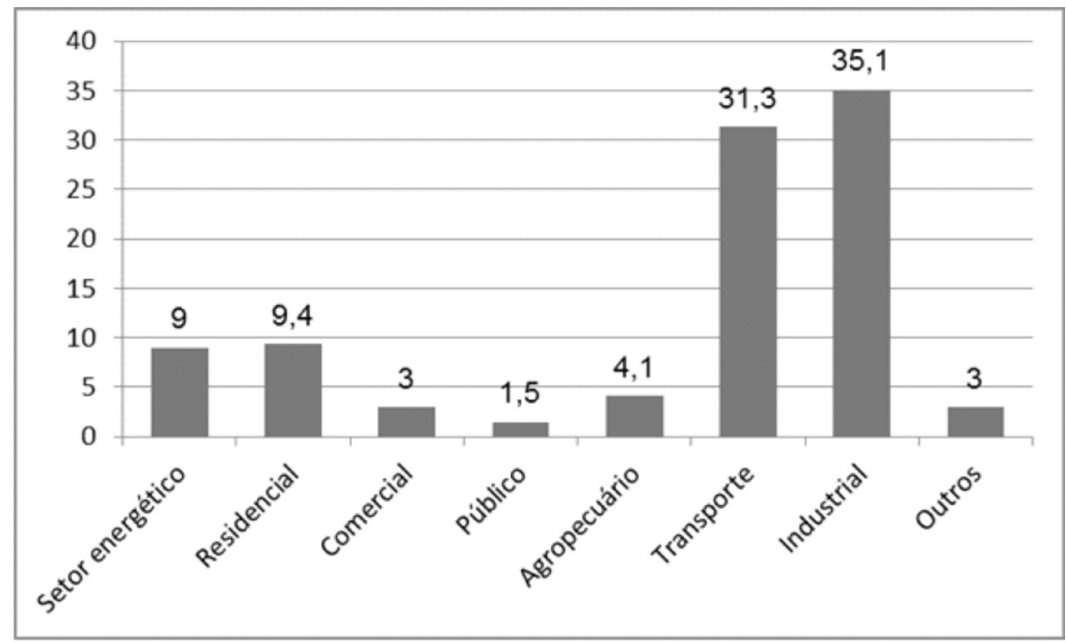

Fonte: Ministério de Minas e Energia/Empresa de Pesquisa Energética (2013).

O aumento da emissão de GEE do setor energético se deve ao componente transporte, mais especificamente o transporte de cargas, e ao aumento do uso de termoelétricas na geração de energia elétrica. A Tabela 5 mostra como a emissão de GEE em Gg CO2 equivalente aumentou de 191.543 em 1990 para 399.302 em 2010. A projeção realizada, no âmbito da Lei no $12.187 / 2009$, que instalou a Política Nacional sobre Mudanças de Clima (PNMC), previa uma emissão de $634.000 \mathrm{Gg}$ CO2 equivalente para 2020, caso sejam realizadas as ações previstas na área de mitigação do Plano Decenal de Expansão de Energia (PDE). Do contrário, o cenário (sem ulteriores ações de mitigação) seria de 868.000 Gg CO2 equivalente. O problema é que o PDE não pode ser visto como um plano nacional de mitigação e adaptação às mudanças climáticas para o setor de energia, porque se trata de um plano indicativo (não mandatário), inclusive com revisões anuais.

As emissões, tendo como fonte a energia, são definidas pelo Ministério da Ciência, Tecnologia e Inovação (MCTI) como "emissões devido à queima de combustíveis e emissões fugitivas da indústria de petróleo, gás e carvão mineral". Sua trajetória pode ser observada na Tabela 15.

Do total das emissões do setor de energia em 2013, o setor de transporte foi responsável por $47 \%$, embora sua participação relativa no consumo de energia seja de $32 \%$. Isso se deve ao uso intenso de energias fósseis no transporte de carga (óleo 
diesel). A Tabela 16 faz uma comparação entre consumo de energia e participação nas emissões de GEE dos setores de transportes, indústria e consumo residencial, referente ao ano 2013.

Tabela 15: Emissões de GEE em $\mathrm{Cg} \mathrm{CO}_{2}$ equivalente no Brasil

\begin{tabular}{c|c|c|c}
\hline & Energia & Total & Total em \% \\
\hline 1990 & 191.543 & 1.392 .756 & $13,75 \%$ \\
\hline 1995 & 232.430 & 2.615 .162 & $8,9 \%$ \\
\hline 2000 & 301.096 & 2.083 .570 & $14,5 \%$ \\
\hline 2005 & 328.808 & 2.032 .260 & $16,2 \%$ \\
\hline 2010 & 399.302 & 1.246 .477 & $32 \%$ \\
\hline
\end{tabular}

Fonte: Ministério da Ciência, Tecnologia e Inovação (2013)

Tabela 16: Comparação do consumo de energia e participação nas emissões entre os setores, 2013

\begin{tabular}{l|c|c|c}
\hline & $\begin{array}{c}\text { Participação no } \\
\text { consumo total de } \\
\text { energia }\end{array}$ & $\begin{array}{c}\text { Participação } \\
\text { nas emissões } \\
\text { relacionadas } \\
\text { ao consumo de } \\
\text { energia }\end{array}$ & $\begin{array}{c}\text { Participação de } \\
\text { renováveis no uso } \\
\text { de energia por } \\
\text { setor }\end{array}$ \\
\hline Transportes & $32 \%$ & $47 \%$ & $17 \%$ \\
\hline Indústria & $33,9 \%$ & $19,4 \%$ & $56 \%$ \\
\hline Consumo residencial & $9,1 \%$ & $3,9 \%$ & $62 \%$ \\
\hline
\end{tabular}

Fonte: Elaboração própria a partir da Empresa de Pesquisa Energética (2014).

\section{E o pré-sal?}

As descobertas do pré-sal, anunciadas oficialmente em novembro de 2007, transformaram a posição do Brasil nas projeções futuras do mercado de petróleo e de gás (P\&G) global. O Brasil vai poder substituir suas importações e se tornar um grande exportador. Não há, em princípio, nenhuma contradição inerente entre a exploração dessas riquezas e o compromisso para avançar rumo a uma economia de baixo carbono. Isso depende do gerenciamento das riquezas e das estratégias de exploração e produção. Riquezas finitas podem contribuir com o financiamento dessa transição. Há de se reconhecer os vários riscos ${ }^{11}$, no contexto deste estudo, em particular os desafios de não sujar a matriz. Um aspecto central

\footnotetext{
${ }^{11}$ Para uma visão global dos desafios e oportunidades do pré-sal, ver Schutte (2014b).
} 
é resistir a pressões para manter o preço dos derivados estruturalmente abaixo dos preços de oportunidade, ou seja, os preços internacionais. Caso contrário, há um incentivo explícito ao desperdício, de um lado, e, de outro lado, desincentivo ao uso e investimento em combustíveis alternativos, em particular o etanol. Além disso, trabalhar de forma estrutural com preços inferiores aos preços internacionais deve ser caracterizado como sendo renúncia fiscal, um subsídio indireto, de caráter regressivo. Haverá grandes pressões para que sejam socializadas as riquezas do présal e que isso se reflita no preço do combustível, ainda mais nos momentos de aumento dos preços internacionais, quando o repasse para o mercado interno pode causar pressões inflacionárias e conflitos sociais. O Brasil já estava enfrentando esse debate desde 2011, quando o governo optou por não repassar o aumento dos preços internacionais do petróleo e, com isso, contribuiu para o enfraquecimento da competitividade do etanol, gerando um desincentivo a investimentos no setor de renováveis, embora existam outros fatores que devam ser levados em conta para analisar a queda significativa de oferta do etanol naquele período.

\section{Transporte}

Um dos principais desafios hoje no Brasil é o setor de transportes, um dos maiores responsáveis pelas emissões de GEE no mundo e que, portanto, em tese, oferece as maiores oportunidades para ações de mitigação. O Brasil ainda sofre com a vitória histórica dos rodoviaristas sobre os ferroviaristas, consolidada na década de 1950. Além disso, há uma subutilização do transporte hidroviário e do potencial de transporte de carga por meio de cabotagem. A Tabela 17 mostra as emissões de GEE do setor de energia pelos subsetores e evidencia o grande peso dos transportes, mais especificamente o rodoviário.

\section{Tabela 17: Evolução das emissões de GEE no Brasil ( $\left.\mathrm{CO}_{2} ; \mathrm{CH}_{4} ; \mathrm{N}_{2} \mathrm{O}\right)$ em $\mathrm{Gg}$}

\begin{tabular}{c|c|c|c|c}
\hline & & $\mathbf{2 0 0 0}$ & $\mathbf{2 0 0 6}$ & $\mathbf{2 0 1 0}$ \\
\hline \multirow{3}{*}{$\begin{array}{c}\text { Subsetores produtores } \\
\text { de energia }\end{array}$} & $\mathrm{CO} 2$ & 43.595 & 49.324 & 58.345 \\
\cline { 2 - 5 } & $\mathrm{CH} 4$ & 124,8 & 167,6 & 198,2 \\
\cline { 2 - 5 } & $\mathrm{N} 2 \mathrm{O}$ & 1,2 & 1,6 & 1,9 \\
\hline \multirow{3}{*}{ Subsetor industrial } & $\mathrm{CO} 2$ & 71.115 & 80.135 & 98.940 \\
\cline { 2 - 5 } & $\mathrm{CH} 4$ & 53,97 & 73,35 & 86,77 \\
\cline { 2 - 5 } & $\mathrm{N} 2 \mathrm{O}$ & 4,3 & 5,5 & 6,54 \\
\hline \multirow{3}{*}{ Subsetor transporte } & $\mathrm{CO} 2$ & 120.130 & 133.431 & 160.180 \\
\cline { 2 - 5 } & $\mathrm{CH} 4$ & 11,5 & 10,3 & 12,3 \\
\cline { 2 - 5 } & $\mathrm{N} 2 \mathrm{O}$ & 2,4 & 2,9 & 3,5 \\
\hline
\end{tabular}




\begin{tabular}{c|c|c|c|c}
\hline & & $\mathbf{2 0 0 0}$ & $\mathbf{2 0 0 6}$ & $\mathbf{2 0 1 0}$ \\
\hline \multirow{3}{*}{ Subsetor residencial } & $\mathrm{CO} 2$ & 17 & 15,7 & 18,6 \\
\cline { 2 - 5 } & $\mathrm{CH} 4$ & 61,6 & 78,3 & 92,6 \\
\cline { 2 - 5 } & $\mathrm{N} 2 \mathrm{O}$ & 1,1 & 1,4 & 1,7 \\
\hline \multirow{3}{*}{ Total $^{12}$} & $\mathrm{CO}^{13}$ & 289.958 & 321.214 & 382.698 \\
\cline { 2 - 5 } & $\mathrm{CH} 4$ & 388,49 & 517,5 & 577,18 \\
\cline { 2 - 5 } & $\mathrm{N} 2 \mathrm{O}$ & 9,6 & 12 & 14,5 \\
\hline
\end{tabular}

Fonte: Ministério da Ciência, Tecnologia e Inovação (2013).

Assim, a nova particularidade da estrutura de emissões do Brasil, em particular do $\mathrm{CO} 2$, consiste no peso do setor de transporte, responsável por cerca de $47 \%$ das emissões do setor de energia (Empresa de Pesquisa Energética, 2014), embora participe com 32\% do consumo total de energia. E, mais ainda, há o peso do transporte rodoviário, responsável por 92\% das emissões de $\mathrm{CO} 2$ do subsetor de transporte, devido à característica brasileira do uso de caminhões para o transporte de carga. A comparação com outro país continental é gritante: a participação do diesel no total de combustíveis nos EUA é de $25 \%$ e no Brasil corresponde a dois terços (Seelke, 2007, p. 10). Essa particularidade da realidade brasileira deve ser objeto de profunda intervenção de políticas públicas, similar à ocorrida para diminuir as queimadas na Floresta Amazônica. De acordo com dados da Agência Nacional de Transportes Terrestres (ANTT), atualizados até abril de 2014, há no Brasil 2.106.716 caminhões em circulação, com idade média de 12,2 anos. Desses, 947.450 são caminhões de autônomos com 16,8 anos de idade média ${ }^{14}$.

O Programa Nacional de Controle da Qualidade do Ar (Pronar), instituído pela Resolução Conama no 5, de 1989, estipulou, entre outras medidas, a implantação do Programa Nacional de Inventários de Fontes Poluidoras do Ar. Mas somente em 2011 foi publicado o primeiro relatório referente a essa temática, com dados das emissões de 1980 a 2009 e projeções até 2020. A Tabela 18 mostra claramente o peso do setor de transporte de carga sobre o total das emissões de GEE pelo setor de transporte rodoviário.

\footnotetext{
${ }^{12}$ Nos valores totais, são ainda consideradas as emissões devido à queima de combustíveis dos subsetores agricultura, comercial e público, como também as emissões fugitivas na mineração de carvão e na extração e transporte de petróleo e gás natural.

${ }^{13} \mathrm{O}$ próprio $\mathrm{MCTI}$ alerta que os dados a respeito das emissões de $\mathrm{CO} 2$ extraídos do Balanço Energético Nacional (BEN) não consideram a queima do carvão mineral importado pelo setor siderúrgico. Se forem consideradas essas emissões, o valor para 2010, por exemplo, aumenta de $382.698 \mathrm{Gg}$ para $406.028 \mathrm{Gg}$.

${ }^{14}$ www.antt.gov.br
} 
Por essas projeções, o total de emissões de CO2 por veículos automotores chegará, em 2020, a 196 milhões de t; dos quais, 131 milhões de t pelo uso do diesel fóssil.

Tabela 18: Cenário da evolução da participação dos vários segmentos nas emissões de GEE dos veículos automotores rodoviários no Brasil

\begin{tabular}{l|c|c|c|c|c|c}
\hline & \multicolumn{2}{|c|}{ CO } & \multicolumn{2}{c|}{ NOx } & \multicolumn{2}{c}{ CO $_{2}$} \\
\hline & 2009 & 2020 & 2009 & 2020 & 2009 & 2020 \\
\hline $\begin{array}{l}\text { Caminhões/ônibus/ } \\
\text { veículos comerciais }\end{array}$ & $17 \%$ & $26 \%$ & $92 \%$ & $93 \%$ & $62 \%$ & $60 \%$ \\
\hline Automóveis leves & $48 \%$ & $51 \%$ & $8 \%$ & $7 \%$ & $35 \%$ & $37 \%$ \\
\hline Motocicletas & $35 \%$ & $23 \%$ & - & - & $3 \%$ & $3 \%$ \\
\hline Total & $100 \%$ & $100 \%$ & $100 \%$ & $100 \%$ & $100 \%$ & $100 \%$ \\
\hline
\end{tabular}

Fonte: Ministério de Minas e Energia (2011).

O Plano Setorial de Transporte e de Mobilidade urbana para mitigação e adaptação à mudança do clima (PSTM), elaborado no âmbito da Política Nacional sobre Mudança do Clima, baseou-se no Plano Nacional de Logística e Transportes (PNLT) ${ }^{15}$ para projetar um cenário de gradual diminuição da participação da modalidade rodoviária, de 60\%, em 2010, para 46\%, em 2031, embora em termos absolutos se projete quase uma duplicação da carga transportada por tal modalidade, conforme pode ser observado na Tabela 19.

Tabela 19: Projeção da evolução do carregamento de carga por modalidade 20102031 no Brasil

\begin{tabular}{l|c|c|c}
\hline & $\mathbf{2 0 1 0}$ & $\mathbf{2 0 2 0}$ & $\mathbf{2 0 3 1}$ \\
\hline Rodoviário & 634 & 908 & 1171 \\
\hline Ferroviário & 278 & 674 & 956 \\
\hline Aquaviário & 131 & 279 & 401 \\
\hline Total & 1043 & 1861 & 2528 \\
\hline
\end{tabular}

Fonte: Elaboração própria a partir do PSTM (2012), baseada no PNLT (2011).

As emissões projetadas do transporte de cargas no cenário de referência deverão atingir 101 milhões de toneladas de dióxido de carbono $\left(\mathrm{MtCO}_{2}\right)$ em 2020 , representando um crescimento de $46,38 \%$ em relação ao ano-base 2010 . E o transporte rodoviário responderá por $89 \%$ das emissões, seguido pelo ferroviário,

${ }^{15}$ O primeiro PNLT foi lançado em 2007 como indutor do Programa de Aceleração do Crescimento (PAC) para as obras rodoviárias, ferroviárias e aquaviárias. Foi elaborado pelo Centro de Excelência em Engenharia de Transportes (Centran), ligado ao Ministério da Defesa, junto com o Ministério dos Transportes. 
com 8\%, e pelo aquaviário, com 3\%. Já em 2031, as emissões somarão $130 \mathrm{MtCO}_{2}$, um aumento de $88,4 \%$ em relação ao ano base 2010 , sendo que o modo rodoviário responderá por $88 \%$ das emissões, o ferroviário, $8 \%$, e o aquaviário, 4\% (MINISTÉRIO DAS CIDADES; MinistÉRIO dos TRANSPORTES, 2013). Os dados mostram a extrema dificuldade do Brasil para enfrentar a herança da concentração do transporte de carga nos rodoviários. Há de se observar, ainda, que o Plano Nacional de Logística e Transportes, assim como o Plano Decenal de Expansão de Energia (PDE), tem caráter indicativo e não vinculativo, o que levanta, inclusive, a questão da viabilização dos recursos necessários à consecução das ações ali previstas.

Com relação ao setor de transporte, há, portanto, uma série de desafios: aumento da malha ferroviária, melhoria da eficiência dos motores dos automóveis, melhoria da gestão do tráfego, estímulo ao uso do transporte coletivo, intensificação do uso de biocombustível e aumento da eficiência energética no geral. Essa preocupação não é nova. Diante do segundo choque de petróleo, em 1979, foi lançado o Programa de Economia de Combustíveis (Peco), formalizado mediante protocolo firmado entre o Governo Federal e as montadoras (Associação Nacional dos Fabricantes de Veículos Automotores - Anfavea) e implementado entre 1983 e 1986. As metas de redução de consumo e ganho de eficiência foram atingidas no período. Porém, com a queda dos preços do petróleo a partir de 1985, esse programa perdeu prioridade e foi descontinuado em 1987. De outro lado, em 1986 houve a Resolução do Conselho Nacional do Meio Ambiente (Coname) do Programa de Controle de Poluição do Ar por Veículos Automotores (Proconve), posteriormente consolidada pela Lei no 8.723/93, de outubro de 1993, e diversas resoluções complementares da própria Coname, limitando as emissões dos veículos novos.

Desde o fim da década de 1980, veículos automotores comercializados no Brasil são avaliados quanto ao limite de emissões atmosféricas pelo Proconve, executado pelo Instituto Brasileiro de Meio Ambiente e Recursos Naturais Renováveis (Ibama). Em 2001, a Lei no 10.295, que dispõe sobre a Política Nacional de Conservação e Uso Racional de Energia, criou um Comitê Gestor de Indicadores e Níveis de Eficiência Energética (CGIEE) ${ }^{16}$, que tem, entre suas atribuições, elaborar uma regulamentação específica para cada tipo de aparelho e máquina consumidora de energia. A partir de 2005, foram incluídos os veículos leves. De fato, os programas

\footnotetext{
${ }^{16}$ O CGIEE é composto por representantes dos seguintes órgãos e entidades: Ministério de Minas e Energia, que o preside; Ministério da Ciência, Tecnologia e Inovação; Ministério do Desenvolvimento, Indústria e Comércio Exterior; Agência Nacional de Energia Elétrica; Agência Nacional do Petróleo; um representante de universidade brasileira e um cidadão brasileiro, ambos especialistas em matéria de energia, a serem designados pelo Ministro de Estado de Minas e Energia para mandatos de dois anos, podendo ser renovados por mais um período.
} 
de etiquetagem de veículos leves são instrumentos relevantes na experiência internacional para a promoção da eficiência veicular (fuel economy labelling) por darem visibilidade às diferenças de eficiência entre os veículos disponibilizados no mercado e seu impacto energético e ambiental. Uma vez em funcionamento, isso pode e deve desejavelmente induzir à implantação de medidas de diferenciação tributária. A partir de março de 2009, iniciou-se a etiquetagem dos veículos. Mas não se chegou, na verdade, a introduzir a obrigatoriedade da etiquetagem no Brasil. Justificava-se que a estratégia é iniciar com a etiquetagem voluntária, criando o hábito e a exigência do mercado, passando, após a consolidação, à fase compulsória. Ficou evidente que o atraso em introduzir a obrigatoriedade da etiquetagem se devia à resistência das montadoras, o que chama ainda mais atenção se considerarmos que as duas maiores montadoras em operação no Brasil são multinacionais europeias, que lidam com a legislação compulsória da União Europeia. Devido ao fato de a etiquetagem ser voluntária, de modo geral, os consumidores dos veículos leves de uso pessoal estão pouco informados, e mesmo grande parte da imprensa especializada parece ignorar os aspectos de desempenho energético, chamando a atenção dos potenciais compradores apenas para os características estéticas, de conforto e potência. E, obviamente, as montadoras submetem à etiquetagem apenas seus melhores veículos.

A indústria automobilística já sabe o que deve ser feito para reduzir o nível de emissões, porque há tempos já pratica a técnica em seus países de origem. Europa, Estados Unidos e Japão, de onde vêm praticamente todas as montadoras até agora instaladas no Brasil, têm as mais rigorosas leis nesse sentido. A tentativa do setor em protelar medida semelhante no Brasil é porque isso exige de qualquer forma investimentos altos na fabricação local dos motores.

O Brasil perdeu uma oportunidade a partir do final de 2008. Como parte da política de estímulo contra os impactos da crise global, o governo baixou o IPI dos veículos de forma acentuada, sem exigir nenhuma contrapartida das montadoras no que diz respeito à eficiência e emissões, embora houvesse metas para a manutenção do emprego no setor. No período de 2008 a 2012, foram concedidos incentivos tributários em benefício das montadoras de cerca de $\mathrm{R} \$ 9$ bilhões, principalmente para estimular a compra de automóveis. Ficou evidente uma clara falta de coerência entre as políticas tributárias e as políticas voltadas ao desenvolvimento sustentável, em particular a Política de Mitigação das Mudanças Climáticas e a de Meio Ambiente (Instituto de Pesquisa Ambiental da Amazônia, 2013).

A passagem para uma economia de baixa intensidade de carbono deverá ser feita "com o carro andando". Nisso, as normas técnicas e o investimento em tecnologia para mitigar as emissões de gases de efeito estufa serão cruciais, e não há por que o País não se pautar pelas normas mais avançadas do mundo. $O$ fato de que o uso 
do etanol no Brasil diminuiu a emissão de GEE pela frota não é argumento para defender limites menos rigorosos para a gasolina.

Uma tentativa importante do governo para reverter esse quadro foi o Programa de Incentivo à Inovação Tecnológica e Adensamento da Cadeia Produtiva de Veículos Automotores (Inovar Auto), parte do Plano Brasil Maior. O programa é voluntário e foi lançado pelo governo, em outubro de 2012. Entrou em vigor no início de 2013, com validade até final de 2017. Ele aumentou o imposto sobre produtos industrializados (IPI) em 30\% para veículos leves vendidos internamente entre os anos de 2013 a 2017, e prevê isenção para montadoras que aderirem ao programa, cumprindo uma série de contrapartidas, que vão aumentar gradualmente. A meta básica é alcançar uma economia de energia de $12,08 \%$ nos automóveis até 2017 , em relação ao ano base de 2011. O detalhamento das exigências sobre emissões e eficiência energética encontrou resistência por parte das montadoras, que defendiam o máximo de flexibilidade, embora a tecnologia para atingir as metas esteja disponível para as empresas. Em resposta a uma solicitação encaminhada formalmente ao Inmetro, a Coordenação do Programa Brasileiro de Etiquetagem respondeu:

Entendemos que a questão da compulsoriedade praticamente foi resolvida com os critérios do Programa Inovar Auto, do Governo Federal, que é uma política pública de maior abrangência à qual o PBE está servindo como um dos critérios para definir redistribuição tributária. O Inovar Auto praticamente torna a etiquetagem compulsória em $2017^{17}$.

De fato, para evitar o aumento do IPI, o Inovar Auto oferece quatro opções, das quais as montadoras devem escolher três. A avaliação do Inmetro é que, por ser, em tese, a opção que exige menos investimentos, as montadoras optarão com certeza pela etiquetagem.

A experiência europeia demonstrou justamente a necessidade de tornar as metas obrigatórias. Em meados de 1990, a Comissão Europeia aprovou uma estratégia de redução de $\mathrm{CO}_{2}$ dos automóveis, baseada em compromissos voluntários e incentivos fiscais para aumentar a eficiência. Ficou claro, porém, que, embora essa política provocasse melhorias, elas estariam longe do necessário. Diante disso, a Comissão optou por regulação para garantir aplicação homogênea, estabelecendo o limite de 130 gramas de $\mathrm{CO}_{2} / \mathrm{km}$ para chegar depois a 120 gramas de $\mathrm{CO}_{2} / \mathrm{km}$ em 2012. Os carros fabricados a partir de 2021 só poderão emitir um máximo de 95 gramas de $\mathrm{CO}_{2}$ por quilômetro. O objetivo é obrigar a indústria a investir em novas tecnologias no âmbito de uma política industrial, visando aumentar a competitividade em longo prazo.

${ }^{17}$ Inmetro - Resposta solicitação no 537518, 30/04/2014. 
A montadora que não atingir as metas estabelecidas pagará multa baseada no número de unidades vendidas e na quantidade de emissão excedente (SCHUTTE, 2014a).

Observe-se que o Primeiro Inventário de Fontes Poluidores do Ar do Ministério do Meio Ambiente (2011), baseado em dados do Balanço Energético Nacional de 2010, mostra um quadro das emissões da frota atual com relação à emissão média de $\mathrm{CO}_{2}$ por veículos em circulação no Brasil (ver Tabela 20). A expressiva diferença entre a média e as metas para novos veículos, mais eficientes e menos poluentes, está relacionada à velocidade da renovação da frota. Incentivos fiscais podem agilizar esse processo, como mostrou a experiência recente em alguns países.

Tabela 20: Emissão de $\mathrm{CO}_{2}$ por fonte de combustível no Brasil

\begin{tabular}{c|c|c|c|c}
\hline Gasolina A & Etanol Anidro & $\begin{array}{c}\text { Etanol } \\
\text { Hidratado }\end{array}$ & Diesel & GNV \\
\hline $226,9 \mathrm{gr} / \mathrm{l}$ & $123,3 \mathrm{gr} / \mathrm{l}$ & $117,8 \mathrm{gr} / \mathrm{l}$ & $267,1 \mathrm{gr} / \mathrm{l}$ & $199,9 \mathrm{gr} / \mathrm{l}$ \\
\hline
\end{tabular}

Fonte: Ministério do Meio Ambiente (2011).

Estudo encomendado pelo Greenpeace fez também uma simulação, utilizando como parâmetro a meta de eficiência energética europeia para 2021, e comparou esses resultados com o cenário de referência, em que apenas o Inovar Auto seria implantado. Como resultado, pode-se verificar que a implantação da meta europeia no Brasil teria como consequência a redução do consumo de energia dos automóveis em $24,5 \%$ e das emissões de GEE em 23,9\% em 2030. No caso do motor flex-fuel, observa-se ainda mais claramente a necessidade de promover a eficiência veicular, na medida em que esses motores são menos eficientes quando usam álcool. Sem dúvida, o uso de biocombustível exige adaptação não só do motor. Quando se apresentou, por parte do setor produtor, a sugestão de aumentar a mistura do etanol anidro na gasolina de $25 \%$ para $27 \%$, a Anfavea reagiu negativamente, apontando que isso causaria maior desgaste a componentes metálicos e de borracha ${ }^{18}$. A solução desse dilema passa por investimentos para adaptar os automóveis a permitir maior e melhor uso de etanol.

Vale lembrar que o incremento da eficiência veicular é de real interesse para o desenvolvimento da indústria automobilística nacional, porque faz que ela acompanhe com capacidade endógena a evolução tecnológica, aumentando sua competitividade, embora represente um custo adicional em curto prazo.

${ }^{18}$ Estadão 12/04/2014. 


\section{Considerações finais}

A matriz energética relativamente mais limpa, o consumo per capita relativamente baixo e o fato de o Brasil ser um exemplo sem precedentes de um país que conseguiu uma redução drástica de emissão de GEE são fatores que podem desestimular uma reflexão crítica. Corre-se o risco de não incentivar a identificação e o aproveitamento de potenciais para ulteriores avanços rumo a uma economia de baixo carbono. Tanto o não reconhecimento dos avanços realizados quanto a acomodação diante da comparação internacional dificultam a priorização de ações concretas para que o Brasil possa, de fato, se consolidar e afirmar sua posição de liderança na luta global rumo a uma economia de baixo carbono.

Com a queda do desmatamento, houve uma mudança qualitativa na composição de emissões de GEE. A energia, que estava em segundo plano, agora aparece como uma das principais áreas, ao lado da agricultura, o que exige políticas específicas.

O setor de transportes se tornou um dos maiores responsáveis pelas emissões GEE no Brasil, seguindo o padrão de emissões globais. Assim, também oferece as maiores oportunidades para ações de mitigação. O Brasil apostou em mecanismos voluntários para estimular as montadoras a investir em mais eficiência e menos poluição, enquanto a experiência europeia demonstrou a necessidade de tornar as metas obrigatórias. Nisso, normas técnicas e investimento em tecnologia para mitigar as emissões de gases de efeito estufa serão cruciais, e não há por que o País não se pautar pelas regras mais avançadas praticadas no mundo. Entre as prioridades, deve estar o aumento da eficiência do motor flex-fuel.

O grande desafio é enfrentar a herança da concentração do transporte de carga nos rodoviários, uma realidade construída desde a década de 1950. Além do déficit na malha ferroviária, há uma subutilização do transporte hidroviário e do potencial de transporte e carga por meio de cabotagem. 


\section{Referências bibliográficas}

Assunção, J.; Gandour, C. C.; RochA, R. A queda do desmatamento na Amazônia brasileira: preços ou políticas? Climate Policy Iniciative. Rio de Janeiro: PUC-RJ, janeiro 2012.

BERMANN, Célio. Energia no Brasil: para quê? Para quem? São Paulo: Editora Livraria da Física, 2002.

BRASIL. Lei no 12.187 de 29 de dezembro de 2009. Institui a Política Nacional sobre Mudança do Clima (PNMC) e dá outras providências. Planalto, 2009. Disponível em: <http://www.planalto.gov.br/ccivil_03/_ato2007-2010/2009/lei/l12187.htm>. Acesso em: 24 de abril de 2015.

Decreto no 7.390, de 9 de dezembro de 2010. Regulamenta os arts. 6o, 11 e 12 da Lei no 12.187, de 29 de dezembro de 2009, que institui a Política Nacional sobre Mudança do Clima (PNMC), e dá outras providências. Planalto, 2010. Disponível em: <http://www.planalto.gov.br/ccivil_03/_Ato2007-2010/2010/ Decreto/D7390.htm>. Acesso em: 24 de abril de 2015.

CALOU, Silvia Maria. Energia e mudanças climáticas: otimismo e ameaças no fronte brasileiro. In: Motta, Ronaldo Seroa et al. (Org.). Mudança do clima no Brasil: aspectos econômicos, sociais e regulatórios. Brasília: Ipea, 2011.

COMItÊ INTERMINISTERIAL SOBRE MUdANÇA do CLIMA. Plano Nacional sobre Mudança do Clima (PNMC). Brasília, dezembro 2008.

CONFEDERAÇÃO NACIONAL DA INDÚSTRIA (CNI). Relatório Infraestrutura, novembro 2013.

A indústria e o Brasil: energia e competitividade na era do baixo carbono. Brasília: SPR/CNI, 2011.

Oportunidades de eficiência energética para a indústria: uma visão institucional. Brasília, 2010b.

EMPRESA de Pesquisa EnERgétICA. Análise da inserção da geração solar na matriz elétrica brasileira. Rio de Janeiro: EPE, maio de 2012.

Balanço Energético Nacional 2013 - ano base 2012: relatório síntese. Rio de Janeiro: EPE, 2013.

Balanço Energético Nacional 2014 - ano base 2013: relatório síntese. Rio de Janeiro: EPE, 2014.

Fórum de Meio Ambiente do Setor ElÉtrico. Position Paper: o setor elétrico e as mudanças climáticas. 2009. Disponível em: <http://www.fmase.com.br/FMASE/ arquivos/bibliotecavirtual/estudos/position_\%20paper_\%20mudclim30set.pdf > Greenpeace/Centro de Estudos Integrados sobre MeIo Ambiente e Mudanças CLIMÁTICAS. Eficiência energética e emissões de gases de efeito estufa. Abril 2014.

Horizonte Renovável. São Paulo, 2013a.

(R)evolução energética - a caminho do desenvolvimento limpo.

Cenário brasileiro, 2013b. 
instituto de Pesquisa Ambiental da Amazônia. Pegada de Carbono dos gastos tributários. Brasília: Ipam, outubro 2013.

INSTITUTO DE PESQUISA ECONÔMICA APLICAdA. Inserção internacional brasileira: temas de política externa. Livro 3, Vol. 1. Brasília: Ipea, 2010.

International Energy Agency (IEA). Internacional Energy Outlook 2013. Paris, 2013a.

2013b.

Redrawing the Energy-Climate Map. WEO Special Report. Paris,

MinistÉRIO DA CIÊNCIA, TECNOLOGIA E INOVAÇÃo. Estimativas anuais de emissões de gases de efeito estufa no Brasil. Brasília, 2013.

Segundo inventário brasileiro das emissões e remoções antrópicas de gases de efeito estufa. Brasília, 2010.

Ministério das Cidades/Ministério dos TRANSPORTES. Plano Setorial de Transporte e de Mobilidade Urbana para Mitigação e Adaptação à Mudança do Clima (PSTM). Brasília, 2013.

Ministério de Minas e Energia/Empresa de Pesquisa Energética. Plano Decenal de Expansão de Energia 2022. Brasília: MME/EPE, 2013.

Ministério do MeIo AMBIENTE. Primeiro inventário nacional de emissões atmosféricas por veículos automotores rodoviários. Brasília, 2011.

Plano Setorial de Transportes e Mobilidade Urbana. Brasília, 2012.

MINISTÉRIO DOS TRANSPORTES. Plano Nacional de Logística e Transporte. Reavaliação de estimativas e metas. Relatório Final. Brasília, setembro 2012.

Nogueira, Luiz Augusto Horta; Branco, Gabriel Murgel. Promovendo a eficiência energética nos automóveis brasileiros. Relatório para o Conpet. Junho de 2005.

Petrobras. Plano Estratégico 2030. Rio de Janeiro: Petrobras 2014.

SCHUTTE, Giorgio Romano. Segurança Energética e Mudanças Climáticas na União Europeia. In: Contexto Internaiconal. v. 36, n. 1, janeiro/junho $2014 a$.

Panorama do pré-sal: desafios e oportunidades. In: Favareto, A.; Moralez, R. Energia, desenvolvimento e sustentabilidade. Porto Alegre: Editora Zouk, 2014b.

SEELKE, Clare Ribando. Ethanol and other biofuels: Potential for US-Brazil Energy Cooperation. Congressional Research Service, setembro 2007.

TolmASQUIM, Mauricio T.; GUerReIRo, Amilcar E.; GorINI, Ricardo. Matriz energética brasileira. Novos Estudos, 79, novembro 2007.

\section{Giorgio Romano Schutte}

Doutor em Sociologia pela Universidade de São Paulo (USP), Coordenador do Bacharelado em Relações Internacionais e membro do corpo docente do Bacharelado em Ciências Econômicas e do Programa de Pós-Graduação em Ciências Humanas e Sociais da Universidade Federal do ABC (UFABC). Contato: giorgio.romano@ufabc.edu.br 